\title{
Strength Evaluation of Cocos nucifera Fibre Reinforced Concrete
}

\author{
${ }^{1}$ O. D. Atoyebi, ${ }^{2}$ O. M. Osuolale and ${ }^{1}$ E. M. Ibitogbe \\ ${ }^{1}$ Department of Civil Engineering, Landmark University, Omu-Aran, Kwara State, Nigeria \\ ${ }^{2}$ Department of Civil Engineering, Ladoke Akintola University of Technology, \\ Ogbomoso, Oyo State, Nigeria \\ atoyebi.olumoyewa@lmu.edu.ng
}

\begin{abstract}
Agro-waste can be used as raw materials for manufacturing various products after recycling. Different researches have investigated the usefulness of coconut fibers (coir) as a micro-reinforcement in concrete this research is aimed at determining properties of fresh and hardened concrete from Ordinary Portland Cement (OPC) reinforced with coconut fiber (coir) and super plasticizer admixture in the form of liquid soap. The flexural and compressive strength of the Coconut Fiber Reinforced Concrete (CRFC) were evaluated at varying percentages $(0.1,0.3$ and $0.5 \%$ by weight of cement) of fiber. The optimal percentage of fiber for both compressive and flexural strength was determined. It is observed that, there is an increment in the various properties and strength of concrete by the addition of fiber as reinforcement, up to an optimum percentage where the strength starts to drop. The flexural strength was seen to increase considerably by about $17.6 \%$ while the compressive strength improved by $23 \%$.
\end{abstract}

Key words: Agro-waste, coconut fiber, coir, concrete, waste, Civil Engineering

\section{INTRODUCTION}

The recent increase in the rate of industrialization in our countries is having a great impact in the environment both positively and negatively as much as it brings development to the environment, it also, adds to the volume of waste being produced. Wastes produced both industrially and agriculturally which comes from extractive, manufacturing and construction processes upsets the environment and immediate community. A major way out of the menace posed by waste is the recycling of the wastes for various products, various industrial and agricultural wastes have been recycled for different purposes (Sadiq and Atoyebi, 2015; Odeyemi et al., 2017; Atoyebi and Sadiq, 2018; Atoyebi et al., 2018a; Modupe et al., 2018, 2019; Atoyebi et al., 2019) and one of such materials is fibers from shells and fruits (Atoyebi et al., 2018b).

The use of natural fibers in reinforcing concrete can be dated as far back as thousands of years ago with the use of straw to make bricks, poles and mud. Various types of fibers fall into two categories namely man-made fibers and natural fibers (Fordos, 1989; Satyanarayana et al., 1990; Ali, 2011; Verma et al., 2013). Numerous researchers in lots of countries have investigated the replacement of reinforcement in concrete (cement-sand matrix) with natural fibers, the development of new stronger fibers and better fiber reinforced composites with new substitutes (Satyanarayana et al., 1990; Filho et al., 2003; Agopyan et al., 2005; Yalley and Kwan, 2009; Ali, 2011; Atnaw et al., 2011; Ali and Chouw, 2013; Verma et al., 2013; Zakikhani et al., 2014; Ede et al., 2014; Anifowoshe and Nwaiwu, 2016). Natural fibers are readily available, cheap, strong, eco-friendly, light weight, biodegradable and renewable, all these qualities make it a choice for use providing adequate mechanical properties like stiffness and strength at an affordable cost. They come from plants and contain lignocellulosic in nature. Natural fibers despite their wide use in building, construction, packaging and automobile, it is relatively high in moisture absorption and therefore, subjected to chemical treatments to enhance the fiber surface properties.

Coconut (C. nucifera) belongs to the family of the Arecaceae (Palmae), the subfamily Cocoideae. Coconut parts are the core, husk, shell, coconut meat and the coconut water (Fig. 1). A mature coconut consists of 28 wt.\% of coconut meat, $12 \mathrm{wt} \%$ of coconut shell and 35 wt.\% of coconut husk (Ali, 2010; Shreeshail et al., 2014). Coconut fruit is a drupe, not a truenut and it

Corresponding Author: O. D. Atoyebi, Department of Civil Engineering, Landmark University, Omu-Aran, Kwara State, Nigeria, atoyebi.olumoyewa@lmu.edu.ng 


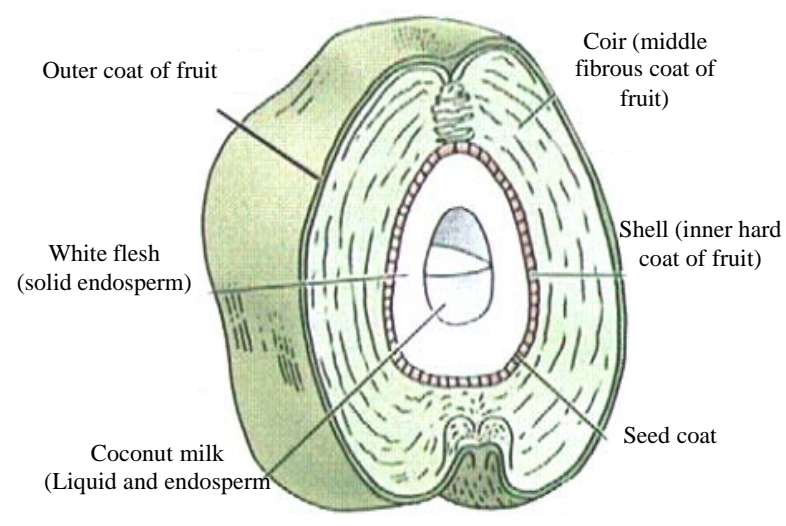

Fig. 1: Parts of a coconut (coconut palm)

comprises of three layers namely the exocarp (outer layer), the mesocarp (middle layer) and the endocarp (inner layer). The exocarp and mesocarp make up the "husk" of the coconut.

Coconut fiber, extracted from the husk is cheap and locally available in many tropical and semitropical countries, this has encouraged many researchers to look into the using of it to enhance the effectiveness of cementitious materials in recent years. Its various uses cut across boards, concrete building (Ali, 2011; Ali and Chouw, 2013) and low-cost roofing materials where coconut fiber was used as reinforcement for cementitious composites and cast under 1-2 MPa of pressure. It has been discovered in researches that the retentive and strong water absorptive nature of coconut fibre influences its reinforced cementitious mixtures to decrease in workability (Savastano et al., 1999) to improve this defect in coconut fibers some techniques employed are washing and boiling in water, alkali treatment and immersion in slurred silica fume. This study looks into the effect of using coconut fibre as an additive on concrete behavior.

\section{MATERIALS AND METHODS}

The experimental program focused on investigating the properties of fresh and hardened concretes containing locally available coir fibers. A total of (90) $150 \mathrm{~mm}$ cubes and (60) $100 \times 400 \mathrm{~mm}$ beams were cast to measure the density, flexural strength and compressive strength.

The materials used in this research include Cocos nucifera (coconut) fiber, Ordinary Portland Cement $(\mathrm{OPC})$, coarse and fine aggregate. Coconut fiber was sourced from badagry area $\left(6.4316^{\circ} \mathrm{N}, 2.8876^{\circ} \mathrm{E}\right)$ in Lagos State, Nigeria and every other material sourced locally
Table 1: Specimen constituents and identification

\begin{tabular}{ll}
\hline Specimen constituents & Specimen $\mathrm{D}$ \\
\hline Concrete with no fiber & $\mathrm{S} 0$ \\
Concrete with $0.1 \%$ fiber & $\mathrm{S} 0.1$ \\
Concrete with $0.3 \%$ fiber & $\mathrm{S} 0.3$ \\
Concrete with $0.5 \%$ fiber & $\mathrm{S} 0.5 \%$ \\
Concrete with $0.1 \%$ fiber $+1 \%$ admixture & $\mathrm{A} 1 \mathrm{~S} 0.1 \%$ \\
Concrete with $0.1 \%$ fiber $+2 \%$ admixture & $\mathrm{A} 2 \mathrm{~S} 0.1 \%$ \\
Concrete with $0.3 \%$ fiber $+1 \%$ admixture & $\mathrm{A} 1 \mathrm{~S} 0.3 \%$ \\
Concrete with $0.3 \%$ fiber $+2 \%$ admixture & $\mathrm{A} 2 \mathrm{~S} 0.3 \%$ \\
Concrete with $0.5 \%$ fiber $+1 \%$ admixture & $\mathrm{A} 1 \mathrm{~S} 0.5 \%$ \\
Concrete with $0.5 \%$ fiber $+2 \%$ admixture & $\mathrm{A} 2 \mathrm{~S} 0.5 \%$ \\
\hline
\end{tabular}

from Omuaran area in Kwara State $\left(8.1402^{\circ} \mathrm{N}, 5.096^{\circ} \mathrm{E}\right)$, Nigeria. Ratio 1:2:4 was used as the concrete mix ratio and the water-cement ratio is 0.6 . The cement properties were in conformity to the requirement of ASTM Type I (ASTM., 2018). Coconut fibers were extracted from the coconut husk which consists of fiber with various diameters, cutting and hand picking operations on the sheath was used too btaina fiber of $40 \mathrm{~mm}$ length and added at proportions $(0.1,0.3$ and $0.5 \%$, respectively) by mass of total cement used (Table 1).

\section{Experimental tests}

Slump test: Slump test was carried out on each batch of concrete to determine its work ability and consistency and was done as specified in ASTM C-1 43 (ASTM., 2015). The apparatus for executing the slump test basically consists of a metallic mould in the form of a frustum of a cone known as slump cone having the internal dimensions of bottom diameter $20 \mathrm{~cm}$, top diameter $10 \mathrm{~cm}$ and a height of $30 \mathrm{~cm}$.

Compressive strength test: This testis carried out to determine the strength or the resistance of the concrete to direct (axial) loading. The test was carried out on the $150 \times 150 \times 150 \mathrm{~mm}$ cubes at the concrete laboratory according to BS 1881-part 116 (Anonymous, 1983). The specimens were tested by compression testing machine after 7,14 and 28 days of curing. They were removed from the water and excess water wiped off and then placed on the bearing surface of the compression machine with the smooth surface facing the front. The load was applied on the specimen gradually to failure point at a rate of $25 \mathrm{kPa}$ per sec.

Flexural strength test: Flexural test also known as Modulus of Rupture (MOR) was carried out on the beams samples to determine their flexural strength resistance to bending. The third-point load test was used for this experiment. Flexural strength of concrete is considered as an index of tensile strength of concrete. Tensile stresses 
are likely to develop in concrete due to rusting of steel reinforcement, drying shrinkage, temperature gradients and many other reasons. In beam flexural tests, theoretical maximum tensile strength is obtained at the bottom of the beam and is called modulus of rupture which depends on the dimension of beam and position of loading.

\section{RESULTS AND DISCUSSION}

Test on fresh concrete: Slump conetest was carried out on the fresh concrete mix to determine the work ability of normal concrete along with CFRC mix. Figure 2 shows that there was a drop in height of slump as the fiber content increase show ever the addition of the admixture produced arise in the height of thes lump. The highest value of slump was $148 \mathrm{~mm}$ for $2 \%$ admixture for the control. The slump for the $0 \%$ fibre content increased by 13.64 for $1 \%$ admixture and 34.5 for $2 \%$ admixture.

Compressive strength test: From Table 2 Specimen S0.1\% gives the highest compressive strength value for 28 days.

Flexural test: This test was designed and carried out to determine the MOR for each specimen. Table 3 gives a summary of these results. From Table 4 above Specimen S0.3\% gives the highest MOR value for 28 days (Fig. 3).

Density determination test: The mass for each cube specimen was taken and recorded and the average determined as the ratio of their respective mass to volume. The average values for the samples ranged from $2283.3-2554.7 \mathrm{~kg} / \mathrm{m}^{3}$ which is very similar to the value of density for concrete $\left(2400 \mathrm{~kg} / \mathrm{m}^{3}\right)$. The variation may be due to improper compaction of

Table 2: Mean compressive strength for 7,14 and 28 days

\begin{tabular}{lccc}
\hline Specimen $(\%)$ & 7 days $\left(\mathrm{N} / \mathrm{mm}^{2}\right)$ & 14 days $\left(\mathrm{N} / \mathrm{mm}^{2}\right)$ & 28 days $\left(\mathrm{N} / \mathrm{mm}^{2}\right)$ \\
\hline S0 & 19.34 & 21.22 & 25.53 \\
S0.1 & 20.41 & 26.01 & 31.37 \\
S0.3 & 17.48 & 19.74 & 23.22 \\
S0.5 & 18.31 & 22.37 & 28.08 \\
A1S0.1 & 18.57 & 21.14 & 27.23 \\
A2S0.1 & 20.55 & 17.59 & 30.42 \\
A1S0.3 & 20.67 & 24.05 & 30.00 \\
A2S0.3 & 21.70 & 23.60 & 28.08 \\
A1S0.5 & 21.10 & 25.79 & 28.97 \\
A2S0.5 & 20.20 & 27.05 & 29.99 \\
\hline
\end{tabular}

Table 3: Summary of flexural test carried out on specimen \begin{tabular}{llll}
\hline Specimen $(\%)$ & 7 days $\left(\mathrm{N} / \mathrm{mm}^{2}\right)$ & 14 days $\left(\mathrm{N} / \mathrm{mm}^{2}\right)$ & 28 days $\left(\mathrm{N} / \mathrm{mm}^{2}\right)$ \\
\hline
\end{tabular}

\begin{tabular}{llll}
\hline S0 & 4.79 & 7.19 & 6.83 \\
S0.1 & 5.97 & 7.49 & 7.52 \\
S0.3 & 5.63 & 6.06 & 8.03 \\
S0.5 & 5.19 & 6.59 & 7.34 \\
A1S0.1 & 7.04 & 6.53 & 7.25 \\
A2S0.1 & 5.69 & 6.44 & 7.59 \\
A1S 0.3 & 5.67 & 6.32 & 7.02 \\
A2S 0.3 & 5.19 & 6.59 & 7.34 \\
A1S0.5 & 4.68 & 6.21 & 6.86 \\
A2S0.5 & 5.31 & 6.21 & 7.19 \\
\hline
\end{tabular}

Table 4: Summary of average density values for each specimen

\begin{tabular}{lcc}
\hline Specimen (\%) & Volume $\left(\mathrm{cm}^{3}\right)$ & Average density $\left(\mathrm{kg} / \mathrm{m}^{3}\right)$ \\
\hline S0 & 3375 & 2464.7 \\
S0.1 & 3375 & 2554.7 \\
S0.3 & 3375 & 2490.1 \\
S0.5 & 3375 & 2470.6 \\
A1S0.1 & 3375 & 2283.3 \\
A2S0.1 & 3375 & 2428.2 \\
A1S0.3 & 3375 & 2416.0 \\
A2S0.3 & 3375 & 2474.6 \\
A1S0.5 & 3375 & 2490.1 \\
A2S0.5 & 3375 & 2508.1 \\
\hline
\end{tabular}

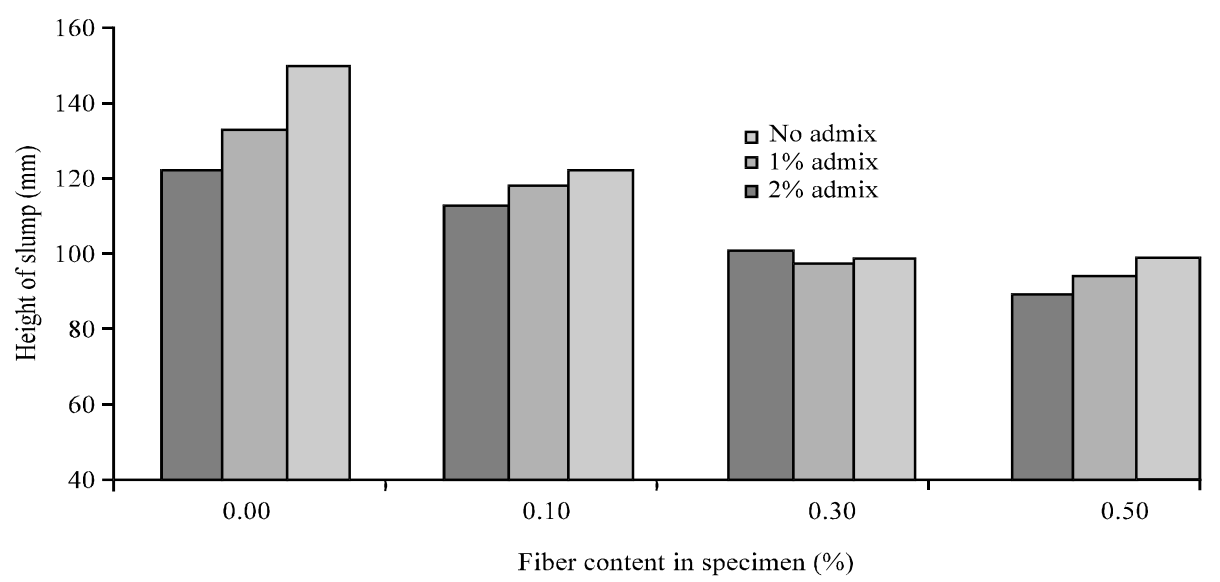

Fig. 2: Slump comparison chart 


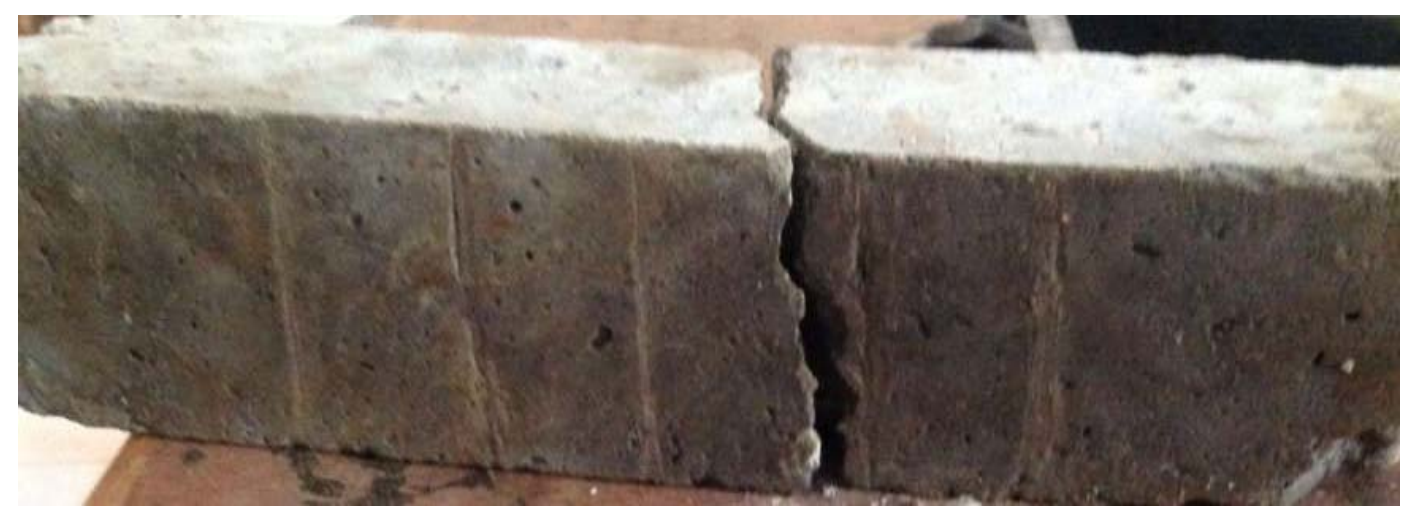

Fig. 3: Beam showing crack after failure due to bending

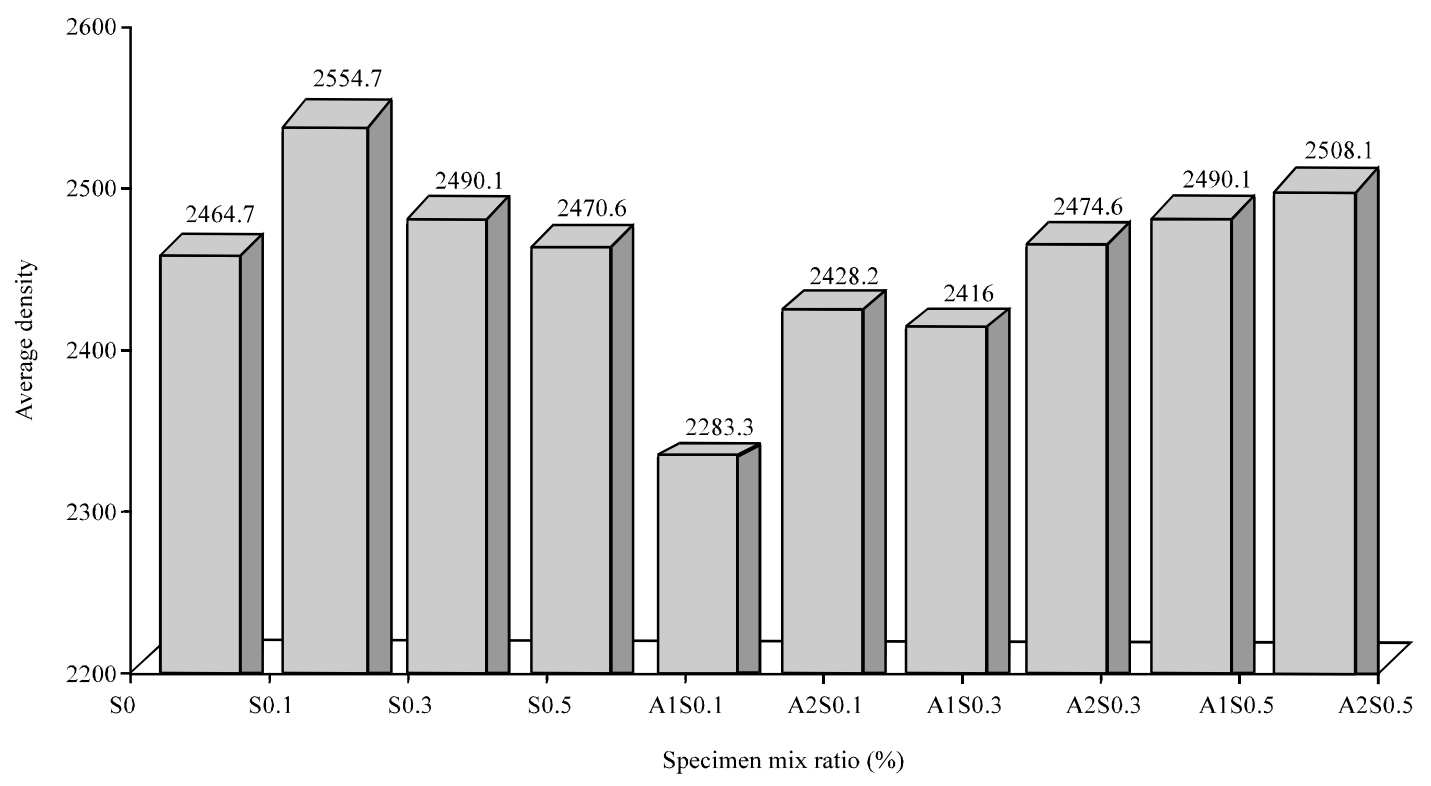

Fig. 4: Comparison of specimen densities

concrete in the mould due to the difference in work ability of the concrete as indicated in the slump test which was carried out. The workability determines how well the concrete will flow and becom pacted. Generally, higher workability points to easier flow and compaction (Fig. 4).

\section{CONCLUSION}

Coconut fiber is obtainable in great quantity at the test site which makes it quite viable as a reinforcement material in concrete. It also acts as a source of income for the producer of coconut who gets the benefits of the new demand made by the construction industry. In addition to this, it is an efficient method for the disposal of coir mattress waste which will reduce the demand for additional waste disposal infrastructure and decrease the load on existing land fills, dump sites and in cinerators. Coconut fibers being natural in origin is ecologically sustainable and can bring down the global carbon foot print quite effectively. After the completion of testing and analysis, the following conclusions can be deduced.

The presence of fibers in concrete generally causes a decrease in the workability of concrete. This is due to the absorption of water when the fiber sare added to the concrete mix. This is deduced from there duction in workability of the concrete mixes. However, the addition of the admixture improved the workability of the variousmix. Flexural strength of the concrete was also 
increased by the addition of fiber into the concrete mix with as high as $17.6 \%$ in the case of $0.3 \%$ coconut fiber content as at 28 days of curing. It had the highest flexural strength of $8.03 \mathrm{~N} / \mathrm{mm}^{2}$. There is an optimum fiber content for every type of mix, at which the concrete at tains the highest strength and beyond which the mechanical strength of concrete mass begins to decrease consistently. This optimum was realized at $0.1 \%$ fiber content for compressive strength. The compressive strength is increased by an average $23 \%$ of coir fiber at $0.1 \%$ having the highest strength $\left(31.37 \mathrm{~N} / \mathrm{mm}^{2}\right)$ as at 28 days of curing.

For samples without admixture, the fiber percentage that generated the highest density was $0.1 \%$ with $2554.7 \mathrm{~kg} / \mathrm{m}^{3}$ while the lowest $0.50 \%$ fiber batch yielded $2470.6 \mathrm{~kg} / \mathrm{m}^{3}$. For specimen swith admixture, the density increased steadily probably as are sult of the use of a concrete mixer to give an even homo genous mix. Higher density values were realised resulting from improved work ability of the mix. Generally, the density of the concrete increased with an increase in the fiber content just up to the optimum fiber percentage after which the density then decreases due to the increase in the volume of voids.

\section{RECOMMENDATIONS}

This research while corroborating the proposition of the positive impact of fibers on concrete focused on the strength and workability of concrete. However, other criteria should be evaluated and looked into: the durability of natural fiber reinforced concrete should be investigated. In addition, impact and abrasive resis tance and chemical resistance test could be carried out, so as to obtain arange of optimum series of the composite to be used in civil construction. Standard extraction of fiber, pre-treatment and transformation into usable products should be considered. Techniques could be developed and the resulting procedure for natural fiber reinforced concrete design standardized.

\section{REFERENCES}

ASTM., 2015. Standard Test Method for Slump of Hydraulic-Cement Concrete. ASTM International, West Conshohocken, Pennsylvania, USA.,.

ASTM., 2018. C150/C150M-18 standard specification for Portland Cement. ASTM International, West Conshohocken, Pennsylvania, USA. https://www. astm.org/DATABASE.CART/HISTORICAL/C150C 150M-18.htm
Agopyan, V., H. Savastano Jr, V.M. John and M.A. Cincotto, 2005. Developments on vegetable fibre-cement based materials in Sao Paulo, Brazil: An overview. Cem. Concr. Compos., 27: 527-536.

Ali, M. and N. Chouw, 2013. Experimental investigations on coconut-fibre rope tensile strength and pullout from coconut fibre reinforced concrete. Constr. Build. Mater., 41: 681-690.

Ali, M., 2010. Coconut fibre-a versatile material and its applications in engineering. Proceedings of the 2nd International Conference on Sustainable Construction Materials and Technologies, June 28-30, 2010, Marche Polytechnic University, Ancona, Italy, pp: 1441-1454.

Ali, M., 2011. Coconut fibre: A versatile material and its applications in engineering. J. Civ. Eng. Constr. Technol., 2: 189-197.

Anifowoshe, F.A. and N.E. Nwaiwu, 2016. The use of coconut fibre ash as a partial replacement for cement. Br. J. Appl. Sci. Technol., 17: 1-11.

Anonymous, 1983. BS 1881 116; Testing concrete: Method for determination of compressive strength of concrete cubes. BSI Group, London, Engalnd, UK. https://www.scribd.com/document/292768848/BS-1 881-116-1983-Testing-Concrete-Method-for-Determ ination-of-Compressive-Strength-of-Concrete-Cubes.

Atnaw, S.M., S.A. Sulaiman and S. Yusup, 2011. A simulation study of downdraft gasification of oil-palm fronds using ASPEN PLUS. J. Applied Sci., 11: 1913-1920.

Atoyebi, O.D. and O.M. Sadiq, 2018. Experimental data on flexural strength of reinforced concrete elements with waste glass particles as partial replacement for fine aggregate. Data Brief, 18: 846-859.

Atoyebi, O.D., A.A. Adediran and A.C. Oluwatimilehin, 2018a. Physical and mechanical properties evaluation of particle board produced from saw dust and plastic waste. Intl. J. Eng. Res. Afr., 40: 1-8.

Atoyebi, O.D., C.O. Osueke, S. Badiru, A.J. Gana and I. Ikpotokin et al., 2019. Evaluation of particle board from sugarcane bagasse and corn cob. Intl. J. Mech. Eng. Technol., 10: 1193-1200.

Atoyebi, O.D., T.F. Awolusi and I.E. Davies, 2018 b. Artificial neural network evaluation of cement-bonded particle board produced from red iron wood (Lophira alata) sawdust and palm kernel shell residues. Case Stud. Constr. Mater., 9: 1-11.

Ede, A.N., O.A. Samuel, I.U. Emmanuel and P.D.E. Chidozie, 2014. Life cycle assessment of environmental impacts of using concrete or timber to construct a duplex residential building. IOSR J. Mech. Civ. Eng., 11: 62-72. 
Filho, R.D.T., K. Ghavami, G.L. England and K. Scrivener, 2003. Development of vegetable fibre-mortar composites of improved durability. Cem. Concr. Compos., 25: 185-196.

Fordos, Z., 1989. Natural or modified cellulose fibers as reinforcement in cement composites. Concr. Technol. Des., 5: 173-207.

Modupe, A.E., O.D. Atoyebi, A.O. Basorun, A.J. Gana and J.A. Ramonu et al., 2019. Development and performance evaluation of crumb rubber-bio-oil modified hot mix asphalt for sustainable highway pavements. Intl. J. Mech. Eng. Technol., 10: 273-287.

Modupe, A.E., O.D. Atoyebi, O.E. Oluwatuyi, O.J. Aladegboye and A.A. Busari e $t$ al., 2018. Dataset of mechanical, marshall and rheological properties of crumb rubber-bio-oil modified hot mix asphalt for sustainable pavement works. Data Brief, 21: $63-70$.

Odeyemi, S.O., M.A. Akinpelu, O.D. Atoyebi and R.T. Yahaya, 2017. Determination of load carrying capacity of clay bricks reinforced with straw. Intl. J. Sustainable Constr. Eng. Technol., 8: $57-65$.
Sadiq, O.M. and O.D. Atoyebi, 2015. Flexural strength determination of reinforced concrete elements with waste glass as partial replacement for fine aggregates. NSE. Tech. Trans., 49: 74-81.

Satyanarayana, K.G., K. Sukumaran, P.S. Mukherjee, C. Pavithran and S.G.K. Pillai, 1990. Natural fibre-polymer composites. Cem. Concr. Compos., 12: $117-136$.

Savastano Jr, H., V. Agopyan, A.M. Nolasco and L. Pimentel, 1999. Plant fibre reinforced cement components for roofing. Constr. Build. Mater., 13: 433-438.

Shreeshail, B.H., J. Chougale, D. Pimple and A. Kulkarni, 2014. Effects of coconut fibers on the properties of concrete. Intl. J. Res. Eng. Technol., 3: 5-11.

Verma, D., P.C. Gope, A. Shandilya, A. Gupta and M.K. Maheshwari, 2013. Coir fibre reinforcement and application in polymer composites: A review. J. Mater. Environ. Sci., 4: 263-276.

Yalley, P.P. and A.S.K. Kwan, 2009. Use of coconut fibre as an enhancement of concrete. J. Eng. Technol., 3: 54-73.

Zakikhani, P., R. Zahari, M.T.H. Sultan and D.L. Majid, 2014. Extraction and preparation of bamboo fibre-reinforced composites. Mater. Des., 63: 820-828. 